\title{
COMPOSIÇÃO DE ÁCIDOS GRAXOS EM RAÍZES DE SORGO SOB ESTRESSE DE ALUMÍNIO ( ${ }^{1}$ )
}

\author{
PAULO HENRIQUE PEREIRA PEIXOTO $\left({ }^{2}\right)$; JOSÉ CAMBRAIA $\left({ }^{3}\right)$
}

\begin{abstract}
RESUMO
Este trabalho teve por objetivo determinar a influência do Al sobre a composição de ácidos graxos em raízes de duas cultivares de sorgo [Sorghum bicolor (L.) Moench] com tolerância diferencial ao Al. Após exposição das plantas ao Al, raízes foram coletadas, os lipídios extraídos e determinada sua composição em ácidos graxos. O palmítico e, especialmente, o linoléico foram os principais ácidos graxos identificados nos extratos lipídicos de raízes das duas cultivares, independentemente da presença do Al. Nas plantas tratadas com $\mathrm{Al}$, os teores dos ácidos esteárico e oléico aumentaram apenas na cultivar tolerante, mas os teores do ácido linolênico reduziram nas duas cultivares. Essas alterações na composição de ácidos graxos, o índice de ligações duplas para ácidos graxos contendo 18 carbonos (ILD $\left.{ }_{\mathrm{C} 18}\right)$ e as relações ácidos graxos saturados/ácidos graxos insaturados (AGI/AGS) e ácido linoléico/ácido palmítico (18:2/ 16:0) sugerem que ocorre redução na fluidez dos lipídios da cultivar tolerante, porém aumento na sensível. A redução na fluidez dos lipídios na cultivar tolerante, comparativamente à da sensível sugere ter a cultivar tolerante maior capacidade de reter íons e metabólitos essenciais e, ou limitar a entrada do Al em suas raízes.
\end{abstract}

Palavras-chave: Sorghum bicolor, toxidez de alumínio, tolerância ao alumínio, lipídios.

\section{ABSTRACT \\ FATTY ACID COMPOSITION OF SORGHUM ROOTS UNDER ALUMINUM STRESS}

The objective of this work was to determine Al effect on fatty acid composition of roots from two sorghum (Sorghum bicolor (L.) Moench) cultivars with differential tolerance to aluminum. After exposure to $\mathrm{Al}$, roots were collected, lipids extracted and the fatty acid composition determined. Palmitic and, especially, linoleic acid were the major fatty acids identified in the root lipid extracts of both cultivars, regardless of the presence of aluminum. Stearic and oleic acids contents increase only in the tolerant cultivar, while linolenic acid decreased in both cultivars after Al treatment. These changes in fatty acid composition, as well as in the $\mathrm{C}_{18}$-fatty acid double bound index $\left(\mathrm{DBI}_{\mathrm{C} 18}\right)$ and in the ratios of unsaturated fatty acid/saturated fatty acid (UFA/SFA) and linoleic acid/palmitic acid (18:2/16:0) indicated of a reduction of the lipid fluidity of the tolerant cultivar, but an increase in the sensitive one. The observed reduction in lipid fluidity in the tolerant relative to the sensitive cultivar suggests of a better capacity of the tolerant cultivar to retain essential ions and metabolites and/or to limit the entry of toxic Al ions into roots.

Key words: Sorghum bicolor, aluminum toxicity, aluminum tolerance, lipids.

$\left({ }^{1}\right)$ Parte da Tese de Doutorado em Fisiologia vegetal, apresentada pelo primeiro autor à Universidade Federal de Viçosa (UFV) Viçosa (MG). Projeto financiado pelo CNPq. Recebido para publicação em 5 de novembro de 2007 e aceito em 21 de agosto de 2008 .

$\left({ }^{2}\right)$ Departamento de Botânica, ICB, Universidade Federal de Juiz de Fora, 36036-900 Juiz de Fora (MG). E-mail: paulo.peixoto@ufjf.edu.br $\left(^{*}\right)$ Autor correspondente.

$\left({ }^{3}\right)$ Departamento de Biologia Geral, CCBS, Universidade Federal de Viçosa, 36571-000 Viçosa (MG). Bolsista do CNPq. E-mail: cambraia@ufv.br 


\section{Introdução}

Aproximadamente $40 \%$ das terras cultivadas no mundo são ácidas e, nesses ambientes, íons solúveis de alumínio na forma $\mathrm{Al}\left(\mathrm{H}_{2} \mathrm{O}\right)_{6}{ }^{+3}$, mais comumente referida como $\mathrm{Al}^{3+}$, inibem $\mathrm{O}$ desenvolvimento das plantas e, em particular, o crescimento das raízes (RYAN et al., 1993; PANDA e матsumoto, 2007). A membrana plasmática é considerada um dos principais alvos das perturbações causadas pelo Al no metabolismo celular (CAKMAK e Horst, 1991; RyAn et al., 2007). Em várias espécies vegetais o $\mathrm{Al}$ modifica a composição lipídica das membranas (ZHANG et al., 1997; Liv et al., 2008) e a composição de seus ácidos graxos constituintes (Peixoto et al., 2001; Chaffai et al., 2005). Assim, alterações na composição da membrana plasmática em genótipos tolerantes ao $\mathrm{Al}$ podem representar mecanismos adaptativos, que contribuem para o restabelecimento das propriedades físico-químicas dessas membranas (ZHANG et al., 1997; CHAFFAI et al., 2005).

Estudos relacionados à distribuição espacial da toxicidade causada pelo $\mathrm{Al}$ têm indicado que, nas raízes, o ápice radicular é o alvo primário da ação do Al (Rran et al., 1993; Sivaguru e Horst, 1998). Рeixoto et al. (2001) observaram que em ápices radiculares o Al reduz a fluidez dos lipídios das membranas em duas cultivares de sorgo, mas em grau de intensidade maior na sensível. Todavia, os efeitos do Al sobre outras porções dos tecidos radiculares não foram avaliados (Регхото et al., 2001). O presente estudo teve como objetivos verificar os efeitos do Al sobre a composição de ácidos graxos e sobre a fluidez dos lipídios em tecidos localizados em regiões distanciadas dos ápices radiculares de duas cultivares de sorgo.

\section{Material e Métodos}

No trabalho, foram utilizadas duas cultivares híbridas de sorgo (Sorghum bicolor (L.) Moench): uma tolerante (BR006R) e outra sensível (BR007A) ao Al (Gonçalves, 1998). Plântulas com sete dias foram cultivadas em vasos de polietileno contendo 1,6 L de solução nutritiva de CLARK (1975), pH 4,0, na ausência ou na presença de Al (185 mM, na forma de $\left.\mathrm{Al}_{2}\left(\mathrm{SO}_{4}\right)_{3} .18 \mathrm{H}_{2} \mathrm{O}\right)$. Após dez dias de tratamento, amostras de raízes, de aproximadamente $8 \mathrm{~cm}$ de comprimento (a partir do ápice), foram homogeneizadas, sendo os lipídios extraídos segundo PALTA et al. (1993). Os ácidos graxos presentes foram hidrolisados e, em seguida, transformados em seus respectivos ésteres metílicos, conforme JHAM et al. (1982). Os ésteres metílicos dos ácidos graxos foram quantificados em cromatógrafo a gás equipado com DIC e coluna de $2 \mathrm{~m} \times 2 \mathrm{~mm}$ (d.i.) de FFAP 20\% (w/ w) em Chromosorb W 60/80. As temperaturas do injetor, detector e da coluna foram mantidas em 200, 220 e $230{ }^{\circ} \mathrm{C}$ respectivamente, sendo nitrogênio utilizado como gás de arraste, num fluxo de $20 \mathrm{~mL}$ $\mathrm{min}^{-1}$. Os ácidos graxos foram identificados por comparação com padrões autênticos (SIGMA®). A partir dos resultados, determinaram-se o índice de ligações duplas para ácidos graxos com 18 carbonos (ILD $\left.\mathrm{C}_{\mathrm{C} 18}\right)$, a relação ácidos graxos insaturados/ácidos graxos saturados (AGI/AGS), a relação ácido linoléico/ácido palmítico (18:2/16:0) e a relação ácido linoléico/ácido linolênico (18:2/18:3) (RYYPPÖ et al., 1994; Navari-Izzo et al., 1991; Palta et al., 1993). O experimento foi implantado em delineamento inteiramente casualizado em esquema fatorial $2 \times 2$ (duas cultivares $\mathrm{x}$ presença ou ausência de $\mathrm{Al}$ ), com três repetições.

\section{Resultados e Discussão}

O palmítico e, especialmente, o linoléico foram os principais ácidos graxos constatados na fração total de lipídios extraída do sistema radicular das duas cultivares de sorgo (Sorghum bicolor (L.) Moench), independentemente da presença do $\mathrm{Al}$ na solução nutritiva (Tabela 1). Na ausência de $\mathrm{Al}$, a composição de ácidos graxos não foi diferente entre as cultivares, exceto quanto ao teor de ácido oléico que na cultivar sensível foi $18 \%$ superior ao da tolerante. O tratamento das plantas com Al modificou a concentração de ácidos graxos nas duas cultivares. Na sensível a única modificação significativa foi uma redução de $13 \%$ na concentração de ácido linolênico. Na cultivar tolerante foram observados aumentos de $139 \%$ e $51 \%$ nas concentrações dos ácidos esteárico e oléico, respectivamente, e redução de $23 \%$ na concentração de ácido linolênico. Com essas modificações, causadas pelo tratamento com $\mathrm{Al}$, a cultivar tolerante passou a ter concentrações de ácido palmítico e esteárico 12 e $53 \%$ mais elevadas que a sensível (Tabela 1). Por outro lado, a cultivar sensível passou a ter concentrações de ácido oléico e linoléico 31 e 7\% mais elevadas que a tolerante. As concentrações dos ácidos palmítico, esteárico, oléico e linoléico na cultivar sensível e do palmítico e linoléico na tolerante não foram significativamente alteradas em resposta à adição do Al à solução nutritiva (Tabela 1).

A importância das alterações na composição lipídica das membranas e dos seus ácidos graxos constituintes em resposta ao $\mathrm{Al}$ tem sido recentemente reforçada (RAmOs-DíAz et al., 2007; RYAN et al., 2007; Liv et al., 2008). No presente experimento ficou claro que os ácidos graxos mais abundantes foram, pela 
seqüência, linoléico > palmítico. Todavia, em trabalho realizado anteriormente utilizando uma fração purificada de membrana plasmática extraída de ápices de raízes de plantas das mesmas cultivares de sorgo utilizadas neste experimento, a relação foi palmítico > linoléico (Регхото et al., 2001). Embora a porção distal da região de transição localizada na zona meristemática do ápice radicular $(2-3 \mathrm{~mm})$ seja considerada a região de maior sensibilidade das plantas ao Al (RYAn et al., 1993; Sivaguru e Horst, 1998; ILLÉs et al., 2006), resultados como os verificados neste trabalho também são relatados (ZHANG et al., 1997; Chaffai et al., 2005), confirmando que a composição de ácidos graxos varia com a espécie e com o tipo de tecido analisado (PALta et al., 1993). A avaliação espacial dos efeitos do $\mathrm{Al}$ sobre a composição de ácidos graxos dos lipídios isolados de tecidos localizados desde os ápices radiculares até porções mais distanciadas dessas regiões poderá esclarecer, com maior precisão, a representatividade e os limites de utilização desses materiais em trabalhos de discriminação de cultivares quanto à tolerância ao Al.

Tabela 1. Efeito do Al sobre a composição de ácidos graxos da fração de lipídios totais do sistema radicular de duas cultivares de sorgo (Sorghum bicolor (L.) Moench)

\begin{tabular}{|c|c|c|c|c|c|c|c|}
\hline \multirow{2}{*}{ Cultivar } & \multirow{2}{*}{ Alumínio } & \multicolumn{6}{|c|}{ Composição de ácidos graxos } \\
\hline & & $16: 0\left(^{1}\right)$ & $16: 1$ & 18:0 & $18: 1$ & $18: 2$ & $18: 3$ \\
\hline & $\mu \mathrm{M}$ & 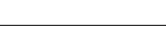 & 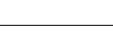 & +2 & 1 & & - \\
\hline \multirow[t]{2}{*}{ Sensível } & 0 & $26,7 \mathrm{Aa}\left({ }^{2}\right)$ & $\mathrm{ND}\left({ }^{3}\right)$ & $2,8 \mathrm{aA}$ & 10,5 aA & 46,1 aA & 17,3 aA \\
\hline & 185 & $24,2 \mathrm{aB}$ & ND & $2,6 \mathrm{aB}$ & $12,9 \mathrm{aA}$ & 48,4 aA & $15,1 \mathrm{bA}$ \\
\hline \multirow[t]{2}{*}{ Tolerante } & 0 & $24,8 \mathrm{aA}$ & ND & $2,3 \mathrm{bA}$ & $5,9 \mathrm{bB}$ & $47,3 \mathrm{aA}$ & $19,4 \mathrm{aA}$ \\
\hline & 185 & $27,5 \mathrm{aA}$ & ND & $5,5 \mathrm{aA}$ & $8,9 \mathrm{aB}$ & $45,2 \mathrm{aB}$ & $14,9 \mathrm{bA}$ \\
\hline
\end{tabular}

(1) 16:0 - ácido palmítico. 16:1 - ácido palmitoléico. 18:0 - ácido esteárico. 18:1 - ácido oléico. 18:2 - ácido linoléico. 18:3 - ácido linolênico.

$\left({ }^{2}\right)$ As médias seguidas pelas mesmas letras minúsculas na cultivar (na ausência ou presença de $\mathrm{Al}$ ) e maiúsculas entre as cultivares (para cada concentração de $\mathrm{Al}$ ), em cada tipo de ácido graxo, não diferem estatisticamente pelo teste de Tukey a $5 \%$ de significância.

$\left({ }^{3}\right)$ ND - Não detectado.

$\mathrm{Na}$ ausência de $\mathrm{Al}$, constataram-se nas cultivares os mesmos valores de $\operatorname{ILD}_{\mathrm{C} 18}$ e da relação 18:2/18:3, mas na cultivar tolerante as relações AGI/ AGS e 18:2/16:0 foram significativamente mais elevadas que na sensível (Tabela 2). Como os valores dessas relações são diretamente proporcionais ao grau de fluidez das membranas (PALTA et al., 1993), é possível concluir que nesta condição, as membranas da cultivar tolerante eram ligeiramente mais fluídas que as da sensível. Após tratamento com $\mathrm{Al}$, observou-se aumento nas relações AGI/AGS, 18:2/16:0 e 18:2/18:3 na cultivar sensível e na relação 18:2/18:3 na cultivar tolerante. Nesta última cultivar, o tratamento com $\mathrm{Al}$ provocou, adicionalmente, redução no índice $\operatorname{ILD}_{\mathrm{C} 18} \mathrm{e}$ nas relações AGI/AGS e 18:2/16:0. O tratamento das plantas com Al modificou a fluidez das membranas das duas cultivares, passando a cultivar sensível a ter maior fluidez pela maioria dos índices considerados.

Tabela 2. Efeitos do Al sobre o $\mathrm{ILD}_{\mathrm{C} 18}$ e sobre as relações AGS/AGI, 18:2/16:0 e 18:2/18:3 de ácidos graxos da fração de lipídios totais do sistema radicular de duas cultivares de sorgo (Sorghum bicolor (L.) Moench)

\begin{tabular}{|c|c|c|c|c|c|}
\hline \multirow{2}{*}{ Cultivar } & \multirow{2}{*}{ Alumínio } & \multicolumn{4}{|c|}{ Relações } \\
\hline & & $\operatorname{ILD}_{\mathrm{C} 18}\left({ }^{1}\right)$ & AGI/AGS $\left({ }^{2}\right)$ & $18: 2 / 16: 0$ & $18: 2 / 18: 3$ \\
\hline & & & . & 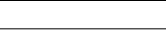 & 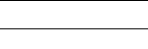 \\
\hline \multirow[t]{2}{*}{ Sensível } & 0 & 1,55 aA $\left({ }^{3}\right)$ & $5,24 \mathrm{bB}$ & $1,73 \mathrm{bB}$ & $2,66 \mathrm{bA}$ \\
\hline & 185 & $1,55 \mathrm{aA}$ & 5,78 aA & $2,01 \mathrm{aA}$ & $3,24 \mathrm{aA}$ \\
\hline \multirow[t]{2}{*}{ Tolerante } & 0 & $1,59 \mathrm{aA}$ & 5,86 aA & $1,91 \mathrm{aA}$ & $2,44 \mathrm{bA}$ \\
\hline & 185 & $1,44 \mathrm{bB}$ & $4,36 \mathrm{bB}$ & $1,64 \mathrm{bB}$ & $3,03 \mathrm{aB}$ \\
\hline
\end{tabular}

(1) $\mathrm{ILD}_{\mathrm{C} 18}$ : Índice de ligações duplas para ácidos graxos de 18 carbonos $=[18: 1+(18: 2 \times 2)+(18: 3 \times 3)]$

$\left({ }^{2}\right)$ AGI/AGS: relação ácidos graxos insaturados/ácidos graxos saturados $=[16: 1+18: 1+(18: 2 \times 2)+(18: 3 \times 3) /(16: 0+18: 0)]$

$\left({ }^{3}\right)$ Médias seguidas pelas mesmas letras minúsculas na cultivar (na ausência ou presença de Al) e maiúsculas entre as cultivares (para cada concentração de

Al), em cada uma das relações, não diferem estatisticamente pelo teste de Tukey a 5\% de significância. 
A composição de ácidos graxos e os valores das relações AGS/AGI, 18:2/18:3, 18:2/16:0 e do índice $\mathrm{ILD}_{\mathrm{C} 18}$, observados neste trabalho, diferiram dos anteriormente constatados por Реіхото et al. (2001). Naquele trabalho, nas frações de membrana provenientes das raízes da cultivar sensível houve menor fluidez. Segundo RYAN et al. (1993), a região de maior sensibilidade das plantas ao Al localiza-se no ápice radicular (2-3 $\mathrm{mm}$ ) e o acúmulo e a secreção de diversas substâncias relacionadas à tolerância ao $\mathrm{Al}$ estão associadas às células dos ápices das raízes (RYAn et al., 1995; BARCEló e PosChenRIEDER, 2002; NAGY et al., 2004; Kochian et al., 2005). A concentração dos efeitos do $\mathrm{Al}$ e a reação das plantas ao estresse parecem mesmo se concentrar nos ápices radiculares, diluindo ou se modificando completamente em porções mais distantes da raiz.

Os resultados constantes deste trabalho corroboram as recomendações de que estudos relacionados à discriminação de genótipos quanto à tolerância ao Al envolvendo alterações na fluidez e composição lipídica das membranas devem se restringir às regiões localizadas próximas aos ápices radiculares, visto que em regiões mais distantes deste ponto focal da toxidez/tolerância ao $\mathrm{Al}$, as modificações podem ser diferentes. Todavia, os efeitos do $\mathrm{Al}$ não se restringem apenas às alterações na composição lipídica e de ácidos graxos (RYAN et al., 2003). Além do enrijecimento da membrana, a peroxidação de lipídios e a indução de estresse oxidativo têm sido associados à ação tóxica do $\mathrm{Al}$ em genótipos sensíveis (Chaffal et al., 2005; PANDA e Матsumoto, 2007; Liv et al., 2008), o que também foi observado por Регхото et al. (1999) utilizando as mesmas cultivares de sorgo e as mesmas porções do sistema radicular analisadas no presente trabalho.

Desde que a cultivar tolerante proporcionou menor fluidez de suas membranas nessa porção da raiz (do ápice até $\pm 8 \mathrm{~cm}$ ), comparativamente à da sensível, mas seu crescimento e outras respostas ao estresse indicaram maior tolerância ao $\mathrm{Al}$ (GONÇALVES, 1998), essas mudanças na sua composição lipídica podem não ser prejudiciais. Duas possibilidades podem ser consideradas para explicar essa aparente contradição: 1) as mudanças na fluidez das membranas nessa porção das raízes não são extremas, isto é, elas passaram a ser ligeiramente mais fluidas e/ou ligeiramente menos fluidas ou; 2) o aumento de fluidez nas membranas dessa região da raiz, ao invés de ser benéfico, como atesta a maioria dos trabalhos (ZHANG et al., 1997; RYAn et al., 2003; Kochian et al., 2005), poderia ser prejudicial à cultivar sensível, permitindo entrar mais $\mathrm{Al}$ e/ou perder mais íons e metabólitos essenciais (CHAFfaI et al., 2005). A validação ou não dessas hipóteses requer a realização de mais pesquisas, principalmente para a avaliação da quantidade de Al acumulada e da perda de eletrólitos em diferentes segmentos de ápices radiculares.

\section{Conclusões}

1. O Al modifica a proporção relativa dos ácidos esteárico, oléico e linolênico nas duas cultivares de sorgo.

2. ILD $_{\mathrm{C} 18}$ e as relações AGS/ AGI, 18:2/16:0 e 18:2/18:3 indicam redução da fluidez nas membranas da cultivar tolerante em resposta ao $\mathrm{Al}$, mas, de modo contrário, aumento da fluidez na cultivar sensível, quando considerados segmentos de raízes com $8 \mathrm{~cm}$ (a partir da ponta da raiz).

\section{Agradecimentos}

Os autores agradecem à Coordenação de Aperfeiçoamento de Pessoal de Ensino Superior (CAPES) e ao Conselho Nacional de Pesquisa (CNPq) pelo suporte financeiro.

\section{Referências}

BARCELÓ, J.; POSCHENRIEDER, C. Fast root growth responses, root exudates, and internal detoxification as clues to the mechanisms of aluminium toxicity and resistance: a review. Environmental and Experimental Botany, Amsterdam, v. 48, n. 2, p. 75-92, 2002.

CAKMAK, I.; HORST, J.H. Effects of aluminum on lipid peroxidation, superoxide dismutase, catalase, and peroxidase activities in root tips of soybean (Glycine max). Physiologia Plantarum, Copenhagen, v. 83, n. 3, p. 463-468, 1991.

CHAFFAI, R.R.; MARZOUK, B.; FERJANI, E.E. Aluminum mediates compositional alterations of polar lipid classes in maize seedlings. Phytochemistry, Oxford, v. 66, n. 16, p. 19031912. 2005.

CLARK, R.B. Characterization of phosphatase of intact maize roots. Journal of Agriculture and Food Chemistry, Washington, v. 23, n. 3, p. 458- 460, 1975.

GONÇALVES, J.F.C. Produção de ácidos orgânicos e tolerância de sorgo à toxicidade do alumínio. 1998. 95f. Dissertação (Mestrado em Fisiologia Vegetal) - Universidade Federal de Viçosa, Viçosa.

ILLÉS, P.; SCHLICHT, M.; PAVLOVKIN, J.; LICHTSCHEIDL, I.; BALUSKA, F.; OVECKA, M. Aluminum toxicity in plants: internalization of aluminum into cells of transition zone in Arabidopsis roots apices related to changes in plasma membrane potential, endosomal behaviour, and nitric oxide production. Journal of Experimental Botany, London, v. 57, n. 15, p. 4201-4213, 2006. 
JHAM, G.N.; TELES, F.F.F.; CAMPOS, L.G. Use of aqueous $\mathrm{HCl} / \mathrm{MeOH}$ as sterification reagent for analysis of fatty acids derived from soybean lipids. Journal of the American Oil Chemistry Society, Champaign, v. 59, n. 3, p. 132-133, 1982.

KOCHIAN, L.V.; PIÑEROS, M.A.; HOEKENGA, O.A. The physiology, genetics and molecular biology of plant aluminum resistance and toxicity. Plant and Soil, Dordrecht, v. 274, n. 1-2, p. 175-195, 2005.

LIU, Q.; YANG, J.L; HE, J.L.S; LI, Y.Y.; ZHENG, S.J. Effect of aluminum on cell wall, plasma membrane, antioxidants and root elongation in triticale. Biologia Plantarum, Praha, v. 52, n. 1, p. 87-92, 2008.

NAGY, N.E.; DALEN, L.S.; JONES, D.L.; SWENSEN, B.; FOSSDAL, C.G. Cytological and enzymatic responses to aluminum stress in root tips of Norway spruce seedlings. New Phytologist, Lancaster, v. 163, n. 3, p. 595-607, 2004.

NAVARI-IZZO, F.; QUARTACCI, M.F.; IZZO, R. Free fatty acids, neutral and polar lipids in Hordeum vulgare exposed to long term fumigation with $\mathrm{SO}_{2}$. Physiologia Plantarum, Copenhagen, v. 81, n. 4, p. 467-472, 1991.

PALTA, J.P.; WHITAKER, B.D.; WEISS, L.S. Plasma membrane lipids associated with genetic variability in freezing tolerance and cold acclimation of Solanum species. Plant Physiology, Rockville, v. 103, n. 3, p. 793-803, 1993.

PANDA, S.K.; MATSUMOTO, H. Molecular physiology of aluminum toxicity and tolerance in plants. The Botanical Review, New York, v. 73, n. 4, p. 326-347, 2007.

PEIXOTO, P.H.P.; CAMBRAIA, J.;SANT'ANNA, R.; MOSQUIM, P.R.; MOREIRA, M.A. Aluminum effects on lipid peroxidation and on the activities of enzymes of oxidative metabolism in sorghum. Revista Brasileira de Fisiologia Vegetal, Brasília, v. 11, n. 3, p. 137-143, 1999.

PEIXOTO, P.H.P.; CAMBRAIA, J.; SANT'ANNA, R.; MOSQUIM, P.R.; MOREIRA, M.A. Aluminum effects on fatty acid composition and lipid peroxidation of a purified plasma membrane fraction of root apices of two sorghum cultivars. Journal of Plant Nutrition, New York, v. 24, n. 7, p. 10611070, 2001

RAMOS-DÍAZ, A.; BRITO-ARGÁEZ, L.; MUNNIK, T.; HERNÁNDEZ-SOTOMAYOR, S.M.H. Aluminum inhibits phosphatidic acid formation by blocking the phospholipase C pathway. Planta, Berlin, v. 225, n. 2, p. 393-401, 2007.

RYAN, P.R.; DELHAIZE, E.; RANDALL, P.J. Malate efflux from root apices and tolerance to aluminium are highly correlated in wheat. Australian Journal of Plant Physiology, Collingwood, v. 22, p., n. 4, 531-536, 1995.

RYAN, P.R.; LIU, Q.; SPERLING, P.; DONG, B.; FRANKE, S.; DELHAIZE, E. A higher plant $\Delta 8$ sphingolipid desaturase with a preference for $(Z)$-isomer formation confers aluminum tolerance to yeast and plants. Plant Physiology, Rockville, v. 144, n. 6, p. 1968-1977, 2007.
RYAN, P.R; DiTOMASO, J.M.; KOCHIAN, L.V. Aluminum toxicity in roots: an investigation of spatial sensitivity and the role of the root cap. Journal of Experimental Botany, London, v. 44, n. 259, p. 437-446, 1993.

RYYPPÖ, A.; VAPAAVUORI, E.M.; RIKALA, R.;SUTINEN, M.L. Fatty acid composition of microsomal phospholipids and $\mathrm{H}^{+}$-ATPase activity in the roots of Scots pine seedlings grown at different root temperatures during flushing. Journal of Experimental Botany, London, v. 45, n. 280, p. 1533-1539, 1994.

SIVAGURU, M.; HORST, W.J. The distal part of the transition zone is the most aluminum-sensitive apical root zone of maize. Plant Physiology, Rockville, v. 116, n. 1, p. 155-163, 1998.

ZHANG, G.; SLASKI, J. J.; ARCHAMBAULT, D. J.; TAYLOR, G. J. Alteration of plasma membrane lipids in aluminiumresistant and aluminium-sensitive wheat genotypes in response to aluminium. Physiologia Plantarum, Copenhagen, v. 99, n. 2, p. 302-308, 1997. 